\title{
Effect of non-solvent additives on the morphology, pore structure, and direct contact membrane distillation performance of PVDF-CTFE hydrophobic membranes
}

\author{
Libing Zheng ${ }^{1,2}$, Zhenjun $\mathrm{Wu}^{3}$, Yong Zhang ${ }^{1,2}$, Yuansong $\mathrm{Wei}^{1,2}$, Jun Wang ${ }^{1,2, *}$ \\ 1. Key Laboratory of Drinking Water Science and Technology, Research Center for Eco-Environmental Sciences, Chinese Academy of Sciences, \\ Beijing 100085, China. E-mail: zhenglibing12@gmail.com \\ 2. Beijing Key Laboratory of Industrial Wastewater Treatment and Resource Recovery, Research Center for Eco-Environmental Sciences, \\ Chinese Academy of Sciences, Beijing 100085, China \\ 3. School of Chemical \& the Environment, Beijing Institute of Technology, Beijing 10008, China
}

\section{A R T I C L E I N F O}

Article history:

Received 27 July 2015

Revised 6 September 2015

Accepted 11 September 2015

Available online 15 February 2016

Keywords:

PVDF-CTFE

Additives

Phase inversion

Membrane distillation

Pre-gelation

\begin{abstract}
A B S T R A C T
Four common types of additives for polymer membrane preparation including organic macromolecule and micromolecule additives, inorganic salts and acids, and the strong non-solvent $\mathrm{H}_{2} \mathrm{O}$ were used to prepare poly (vinylidene fluoride-co-chlorotrifluoroethylene) (PVDF-CTFE) hydrophobic flat-sheet membranes. Membrane properties including morphology, porosity, hydrophobicity, pore size and pore distribution were investigated, and the permeability was evaluated via direct contact membrane distillation (DCMD) of $3.5 \mathrm{~g} / \mathrm{L} \mathrm{NaCl}$ solution in a DCMD configuration. Both inorganic and organic micromolecule additives were found to slightly influence membrane hydrophobicity. Polyethylene glycol (PEG), organic acids, $\mathrm{LiCl}, \mathrm{MgCl}_{2}$, and $\mathrm{LiCl} / \mathrm{H}_{2} \mathrm{O}$ mixtures were proved to be effective additives to PVDF-CTFE membranes due to their pore-controlling effects and the capacity to improve the properties and performance of the resultant membranes. The occurrence of a pre-gelation process showed that when organic and inorganic micromolecules were added to PVDF-CTFE solution, the resultant membranes presented a high interconnectivity structure. The membrane prepared with dibutyl phthalate (DBP) showed a nonporous surface and symmetrical cross-section. When $\mathrm{H}_{2} \mathrm{O}$ and $\mathrm{LiCl} / \mathrm{H}_{2} \mathrm{O}$ mixtures were also used as additives, they were beneficial for solid-liquid demixing, especially when $\mathrm{LiCl} / \mathrm{H}_{2} \mathrm{O}$ mixed additives were used. The membrane prepared with $5 \% \mathrm{LiCl}+2 \% \mathrm{H}_{2} \mathrm{O}$ achieved a flux of $24.53 \mathrm{~kg} /\left(\mathrm{m}^{2} \cdot \mathrm{hr}\right)$ with $99.98 \%$ salt rejection. This study is expected to offer a reference not only for PVDF-CTFE membrane preparation but also for other polymer membranes.

(c) 2016 The Research Center for Eco-Environmental Sciences, Chinese Academy of Sciences.
\end{abstract}

Published by Elsevier B.V.

\section{Introduction}

Hydrophobic membrane preparation has been a hotspot in the membrane preparation and application field with the emergence and development of new hydrophobic membrane-based processes such as membrane distillation (MD), membrane crystallization ( $\mathrm{MCr}$ ), membrane emulsification (ME), osmotic distillation (OD), and membrane gas absorption (MGA) (Cui et al., 2014). Polypropylene (PP), polytetrafluoroethylene (PTFE), and polyvinylidene fluoride (PVDF) are common polymer materials

\footnotetext{
* Corresponding author. E-mail: junwang@rcees.ac.cn (Jun Wang).
} 
for hydrophobic membrane preparation due to their hydrophobic nature and high strength. Among them, PVDF has been the most studied due to its solubility in many common solvents (Alkhudhiri et al., 2012; Liu et al., 2011b). However, it has also showed many defects, especially regarding industrial applications. Although hydrophobic modification of existing membranes or polymers is widely applied to further improve the properties and performance of hydrophobic membranes, seeking or synthesizing a substituted polymer for hydrophobic membranes is another effective way to obtain an ideal membrane (Kang and Cao, 2014). Recently, PVDF-based copolymers like poly (vinylidene fluoride-co-tetrafluoroethylene) (PVDF-TFE), poly (vinylidene fluoride-co-trifluoroethylene) (PVDF-TrFE), poly (vinylidene fluoride-co-hexafluoropropylene) (PVDF-HFP) and some kinds of PVDF-based graft copolymers have been applied in hydrophobic membrane preparation studies (Ameduri, 2009; Cui et al., 2014). These copolymers possess higher hydrophobicity due to their high fluorine content, and have attracted considerable attention as an alternative choice for hydrophobic membrane preparation (Feng et al., 2004, 2006). Poly (vinylidenef luoride-co-chlorotrifluoroethylene) (PVDF-CTFE) also has shown its potential in membrane preparation due to the $\mathrm{C}-\mathrm{Cl}$ bond in the main chain structure (Cui et al., 2014; Feng et al., 2004; Koh et al., 2008; Liu et al., 2011a). However, its application for hydrophobic membrane preparation has been rarely reported to the best of our knowledge. Therefore in this study, it was applied to prepare hydrophobic membranes for MD because it possesses a hydrophobic nature.

Non-solvent induced phase inversion (NIPS), which is also generally known as dry-wet phase inversion, is a commonly applied method for polymer hydrophobic membrane preparation owing to its moderate processing conditions and facile control of membrane structure as compared to other preparation methods, such as thermally induced phase inversion (TIPS) and sintering (Cheng et al., 1999; Liu et al., 2011b). However, the phase inversion process is complicated, especially for semi-crystalline polymers, which may exhibit liquid-liquid (L-L) demixing and solid-liquid (S-L) demixing simultaneously (Cheng, 1999; Cheng et al., 2001; Sukitpaneenit and Chung, 2009). The composition of the casting solution, especially the non-solvent additives, is considered to be the crucial factor for the resultant membrane. The additives may alter the solvation power of the solvent and affect the casting solution in terms of both thermodynamic and kinetic properties (Zheng et al., 2006), which consequently influence the phase inversion process. For semi-crystalline polymers, the selection of additives is especially crucial, because the L-L and S-L demixing, which have significant effects on the resultant membranes, can be easily influenced by the additives.

The additives for polymer membrane preparation can be categorized into different types (Liu et al., 2011b; Mansourizadeh and Ismail, 2011), including macromolecular polymeric additives, micromolecular alcohols or organic acids, inorganic acid or salts, and the strong non-solvent additive, water. Polyvinyl pyrrolidone (PVP) and polyethylene glycol (PEG) are commonly used polymer additives for both hydrophobic and hydrophilic membrane preparation, and they are considered to be strong pore formers. However, other macromolecular additives have also been used in membrane preparation investigations for their strong pore-forming effects. Narbaitz's group has been devoted to synthesis of surface modifying macromolecules (SMMs) for polymer membrane preparation such as cellulose acetate (CA), polyetherimide (PEI), polysulfone (PS), and polyvinylidene fluoride (PVDF) membrane solutions (Dang et al., 2010). Pezeshk et al. (2012) prepared two hydrophilic polyurethane additives, i.e., L2MM (PEG-600) and L2MM (PEG-200), from 4,4'-methylene bis (phenyl isocyanate) (MDI) and PEG, and applied them for PVDF membrane preparation. The permeate flux and separation properties for $100 \mathrm{kDa}$ polyethylene oxide (PEO) were remarkably increased, especially for L2MM (PEG-200).

However, macromolecular additives may not be completely leached out during coagulation and subsequent washing processes, and membrane properties may be greatly affected, especially membrane hydrophobicity. Thus water soluble organic and inorganic micromolecule additives are more appropriate for hydrophobic membrane preparation from this point of view. Organic alcohols and acids like methanol, ethanol, 1-propanol, glycerol, butanol, diethylene glycol, ethylene glycol, acetic acid, methanoic acid, and ethanedioic acid have been investigated in many cases (Feng et al., 2006; Khayet et al., 2002; Mansourizadeh and Ismail, 2011; Shih et al., 1990; Sukitpaneenit and Chung, 2009; Wang et al., 2000). Lithium halides like LiCl, LiBr, and LiF have been researched widely, as well as other lithium salts such as $\mathrm{LiClO}_{4}$ and $\mathrm{LiNO}_{3}$, due to the formation of acid-base complexes between the $\mathrm{LiCl}$ and solvent and the interaction between $\mathrm{Li}^{+}$ ions and electron donor groups of PVDF, which may dramatically affect the phase inversion process during coagulation (Idris et al., 2010; Kurdi and Tremblay, 2001; Wang et al., 2000; Yeow et al., 2005). Other metal salts and inorganic acids such as $\mathrm{ZnCl}_{2}, \mathrm{CaCl}_{2}$, $\mathrm{AlCl}_{3}, \mathrm{NaBr}, \mathrm{KClO}_{4}, \mathrm{Mg}\left(\mathrm{ClO}_{4}\right)_{2}, \mathrm{NaNO}_{3}$, and $\mathrm{H}_{3} \mathrm{PO}_{4}$ have also been evaluated, and due to the strong interaction among additives, solvent, non-solvent, and polymers, these additives have significant effects on the membrane preparation process and the resultant membranes (Kraus et al., 1979; Kurdi and Tremblay, 2001; Mansourizadeh and Ismail, 2011; Noor et al., 2013; Shinde et al., 1999; Yang and Liu, 2003). $\mathrm{H}_{2} \mathrm{O}$ is another commonly used additive with a slight addition in the casting solution. As a strong non-solvent additive, the addition of water may strongly decrease the stability of the casting solution and induce a pre-gelation process before coagulation. Thus crystals may appear in the resultant membrane because of the gelation process, so that the membrane possesses a high interconnectivity structure (Lin et al., 2002; Wang et al., 2000).

More recently, the use of mixed additives was studied to overcome the defects of single additives. $\mathrm{LiCl}$, which has been believed to be a suitable additive, especially for PVDF, was commonly used in mixture with other additives such as $\mathrm{H}_{2} \mathrm{O}$, ethanol, 1-propanol, and PEG. Wang et al. (2000) prepared PVDF asymmetric hollow fiber membranes with the mixed additives water/LiCl, ethanol/LiCl, and 1-propanol/LiCl. An interconnected structure was observed in the hollow fiber prepared from LiCl/ water, while circular nodules appeared in the membrane prepared from LiCl/1-propanol, and the mixed additives water/ $\mathrm{LiCl}$ and 1-propanol/LiCl were found to be able to significantly increase the permeability, mechanical strength and membrane hydrophobicity. Hou et al. (2012b) prepared a PVDF hollow fiber membrane for the DCMD desalination process using the mixed additives LiCl/PEG-1500. They found that the membrane prepared with mixed additives showed longer finger-like cavities, ultra-thin skins, a narrow pore size distribution and porous network sponge-like structure, high porosity and good 
Table 1-Compositions of the polymer solutions for membrane casting.

\begin{tabular}{cccc}
$\begin{array}{c}\text { Membrane } \\
\text { code }\end{array}$ & $\begin{array}{c}\text { PVDF-CTFE } \\
\text { (wt\%) }\end{array}$ & $\begin{array}{c}\text { Additive } \\
\text { (wt\%) }\end{array}$ & $\begin{array}{c}\text { DMAc } \\
\text { (wt\%) }\end{array}$ \\
\hline \multicolumn{2}{c}{ Polymer additives effect } & & \\
P1 & 12 & none & 88 \\
P2 & 12 & PEG-400 (5) & 83 \\
P3 & 12 & PVP K40 (5) & 83
\end{tabular}

Organic micromolecule additive effect

$\begin{array}{llcl}\text { O1 } & 12 & \begin{array}{c}\text { Methanoic acid } \\ \text { (5) }\end{array} & 83 \\ \text { O2 } & & \text { Acetic acid (5) } & 83 \\ \text { O3 } & 12 & \text { Oxalic acid (5) } & 83 \\ \text { O4 } & 12 & \text { Glycol (5) } & 83 \\ \text { O5 } & 12 & \text { Glycerol (5) } & 83 \\ \text { O6 } & 12 & \text { Acetone (5) } & 83 \\ \text { O7 } & 12 & \text { DBP (5) } & 83\end{array}$

Inorganic additive effect

$\begin{array}{llcl}\text { I1 } & 12 & \mathrm{LiCl}(5) & 83 \\ \text { I2 } & 12 & \mathrm{MgCl}_{2}(5) & 83 \\ \text { I3 } & 12 & \mathrm{FeCl}_{3}(5) & 83 \\ \text { I4 } & 12 & \mathrm{NaNO}_{3}(5) & 83 \\ \text { I5 } & 12 & \mathrm{H}_{3} \mathrm{PO}_{4}(5) & 83\end{array}$

Strong non-solvent $\mathrm{H}_{2} \mathrm{O}$ effect

\begin{tabular}{llcl}
$\mathrm{H} 1$ & 12 & $\mathrm{H}_{2} \mathrm{O}(1)$ & 87 \\
$\mathrm{H} 2$ & 12 & $\mathrm{H}_{2} \mathrm{O}(2)$ & 86 \\
$\mathrm{H} 3$ & 12 & $\mathrm{H}_{2} \mathrm{O} / \mathrm{LiCl}(1 / 5)$ & 82 \\
$\mathrm{H} 4$ & 12 & $\mathrm{H}_{2} \mathrm{O} / \mathrm{LiCl}(2 / 5)$ & 81 \\
\hline
\end{tabular}

hydrophobicity owing to the synergistic effects of $\mathrm{LiCl}$ and PEG-1500. Wongchitphimon et al. (2011) also investigated the effect of LiCl/PEG-6000 mixed additives on PVDF-HFP membrane preparation. Application of mixed additives has been an effective method to obtain ideal membranes, and mixed additives using different types of common additives have been widely studied in the membrane preparation field.

However, to the best of our knowledge, although the influence of many types of additives has been widely investigated and some agreements have been achieved, most of them have been studied individually. Comprehensive research to investigate the influence of different types of additives under the same preparation conditions has been rare. Therefore, in this study, different additives covering polymer additives like PVP and PEG, organic micromolecules like methanoic acid, acetic acid, oxalic acid, glycol, glycerol, acetone, dibutyl phthalate (DBP), and inorganic salts and acids like $\mathrm{LiCl}, \mathrm{MgCl}_{2}, \mathrm{FeCl}_{3}, \mathrm{NaNO}_{3}$, and $\mathrm{H}_{3} \mathrm{PO}_{4}$ were used to prepare PVDF-CTFE copolymer hydrophobic membranes. Membrane morphology, porosity, pore size and pore size distribution, hydrophobicity, and performance in a desalination process by DCMD were investigated to evaluate the effect of additives. It is believed that this work will offer a comprehensive perspective on the effect of different additives and offer a reference for PVDF-CTFE as well as other polymer membrane preparation.

\section{Material and methods}

\subsection{Materials}

Commercial PVDF-CTFE copolymer (cataloged as Solef® 32,008) was purchased from Solvay (Belgium). DMAc, obtained from Shanghai Jingwei Chemical Co., Ltd. (Shanghai, China) was employed as the solvent. LiCl, PEG-400 and PVP K40 were supplied by Tianjin Guangfu Research Institute of Fine Chemical Engineering (Tianjin, China). Methanoic acid, acetic acid, oxalic acid, glycol, glycerol, acetone, $\mathrm{DBP}, \mathrm{MgCl}_{2}, \mathrm{FeCl}_{3}, \mathrm{NaNO}_{3}, \mathrm{H}_{3} \mathrm{PO}_{4}$,

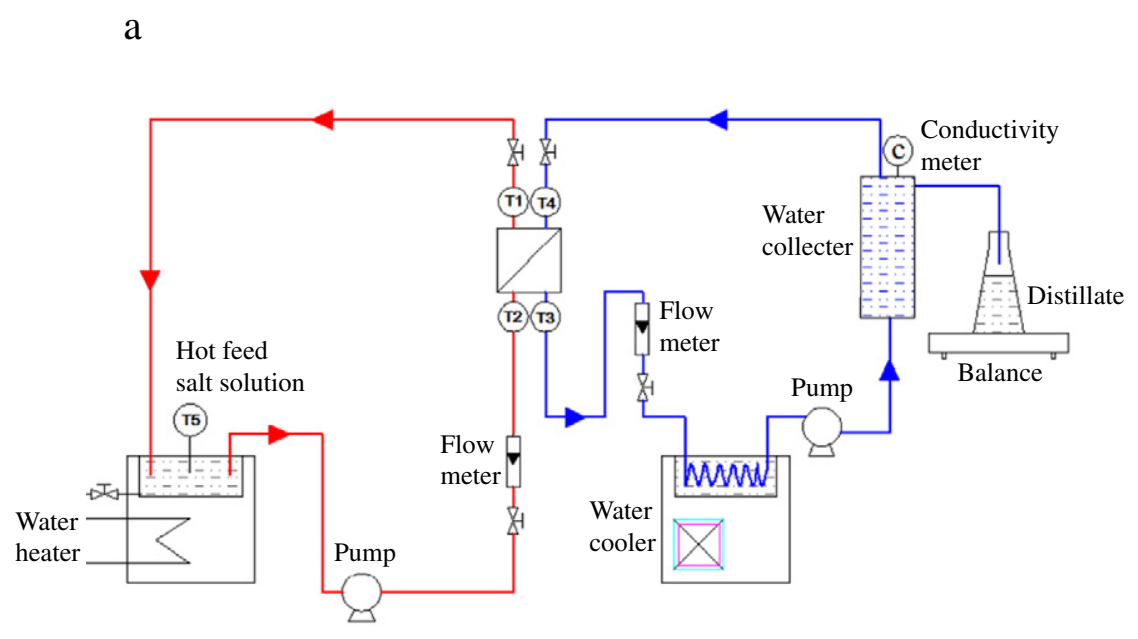

b

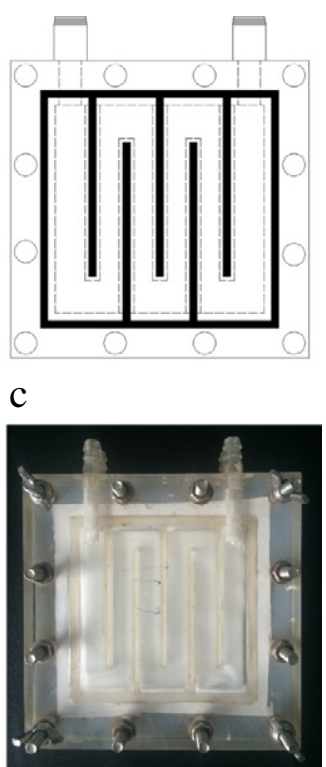

Fig. 1 - (a) Schematic diagram of the DCMD set-up, (b) design diagram of the flat-sheet membrane module, (c) flat-sheet membrane module. 

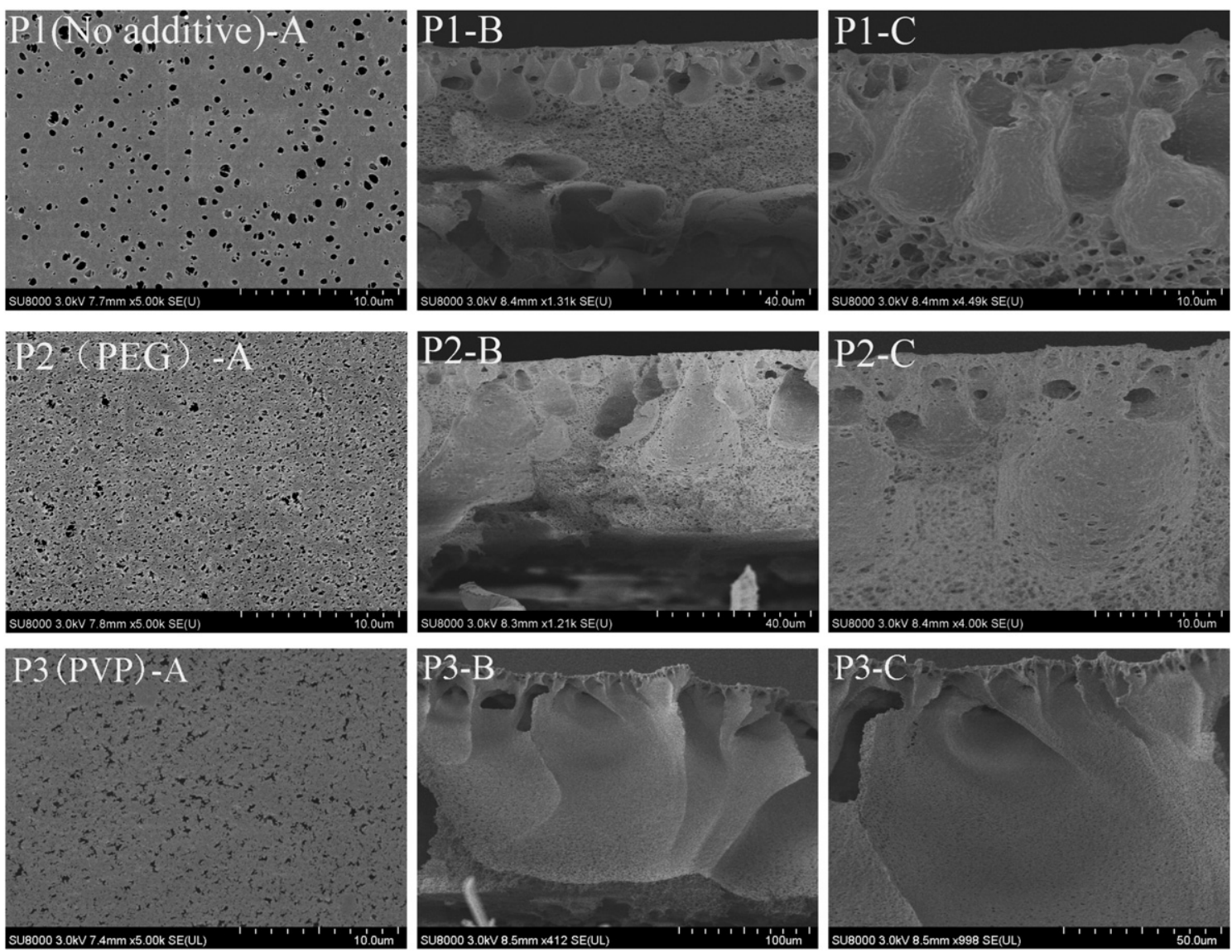

Fig. 2 - Morphology flat-sheet membranes cast from different polymer additives. (A) Membrane surface, (B) cross-section, (C) magnified cross section near membrane surface.

and $\mathrm{NaCl}$ were purchased from Beijing Chemical works (Beijing, China), and all of these reagents were of AR grade and used as received. Deionized water was used as a coagulant for membrane preparation.

\subsection{Membrane preparation}

PVDF-CTFE flat-sheet membrane was prepared by a dry-wet phase inversion process. Before membrane preparation, the PVDF-CTFE powder was dried in a vacuum oven at $50^{\circ} \mathrm{C}$ for $24 \mathrm{hr}$. Then certain amounts of PVDF-CTFE powder, DMAC and different additives were mixed in a sealed flask and vigorously stirred till a homogeneous polymer solution was achieved at $30^{\circ} \mathrm{C}$ (detailed casting solution compositions are shown in Table 1). Subsequently, the homogeneous polymer solution was degassed at $30^{\circ} \mathrm{C}$ in a vacuum oven for $24 \mathrm{hr}$.

A supporting layer, i.e., a piece of hydrophilic polyethylene terephthalate $(\mathrm{PET})$ nonwoven fabric $(18 \mathrm{~cm} \times 20 \mathrm{~cm})$, was attached on a glass plate to prevent shrinkage of the membranes during the drying process and enhance the mechanical strength. Then, polymer solutions were cast uniformly on the surface of the PET nonwoven fabric using a home-made casting knife with a gap of $0.25 \mathrm{~mm}$. The glass plates with polymer solution were immersed into a $25^{\circ} \mathrm{C}$ deionized water bath for coagulation after being exposed in air for $15 \mathrm{sec}$. The nascent membranes were removed from the coagulation bath and peeled off from the glass $24 \mathrm{hr}$ later, then dried in air at room temperature for further applications and measurements.

\subsection{Membrane characterization}

To investigate the effect of different additives on the PVDF-CTFE membranes, membrane properties including morphology, hydrophobicity, porosity, pore size and pore size distribution and the consequent membrane DCMD performance were evaluated. The membrane surface and cross-section morphologies were observed by a field emission scanning electron microscope (FE-SEM) (HITACHI SU8020, Hitachi, Japan) under standard

\section{Table 2 - Essential properties and MD performance of membranes by polymer additives.}

\begin{tabular}{ccccc} 
Membrane code & Mean pore size $(\mu \mathrm{m})$ & Porosity $(\%)$ & CA $_{\text {water }}\left({ }^{\circ}\right)$ & Flux $\left(\mathrm{kg} /\left(\mathrm{m}{ }^{2} \cdot \mathrm{hr}\right)\right)$ \\
\hline P1 & 0.0886 & 63.14 & 97.3 & 13.06 \\
P2 & 0.1227 & 69.08 & 88 & 17.98 \\
P3 & 1.445 & 88.65 & 82.2 & 13 \\
Nonductivity $(\mu S)$ & None & None \\
\hline
\end{tabular}




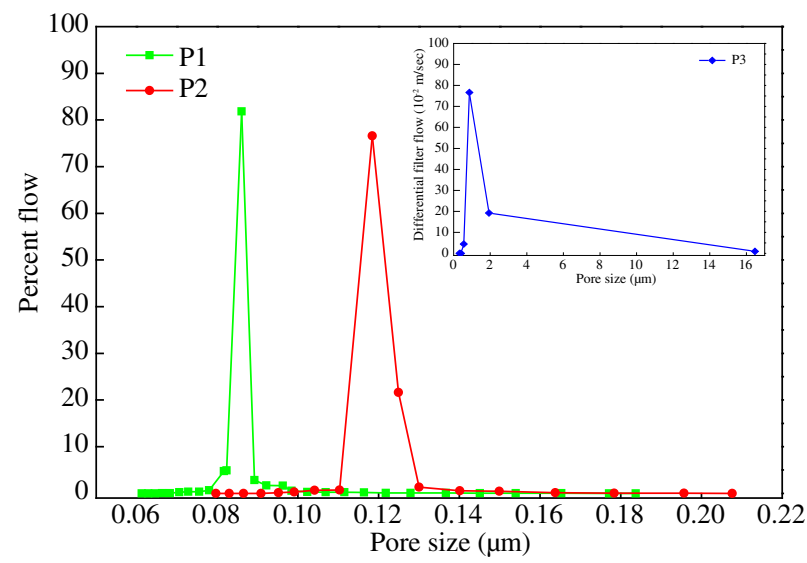

Fig. 3 - Pore distribution of flat-sheet membranes cast from different polymer additives.

high-vacuum conditions at $3.00 \mathrm{kV}$. Liquid nitrogen was used for cryogenic fracturing of the membrane for cross-section observation, and all the samples were coated with a gold nanoparticle layer under vacuum with an Ion Sputtering device
(HITACHI E-1010, Hitachi, Japan), as the membranes were non-conducting.

As a crucial factor in membrane performance and anti-wetting property in MD application, the contact angle with water $\left(\mathrm{CA}_{\text {water }}\right)$ was used to evaluate membrane hydrophobicity. It was measured using an OCA 15EC Video-Based Contact Angle Meter (Data Physics, Germany). Water droplets of about $0.5 \mu \mathrm{L}$ were dropped onto the surface of the flat-sheet membranes through a syringe at ambient temperature and the contact angle was calculated with the aid of an illumination system and software. At least five different positions of each membrane were measured and the average value was reported.

Membrane pore structure is another factor that can influence the membrane permeate flux and salt rejection. In this work, porosity, pore size and pore size distribution were used together to describe the membrane pore structure, as any individual parameter may present an incomplete picture. The porosity of the membrane, defined as the volume proportion of pores over the total volume of the membrane, was measured by the gravimetric method. A $4 \times 4 \mathrm{~cm}^{2}$ membrane sample was torn off from the nonwoven fabric supporting layer and immersed in
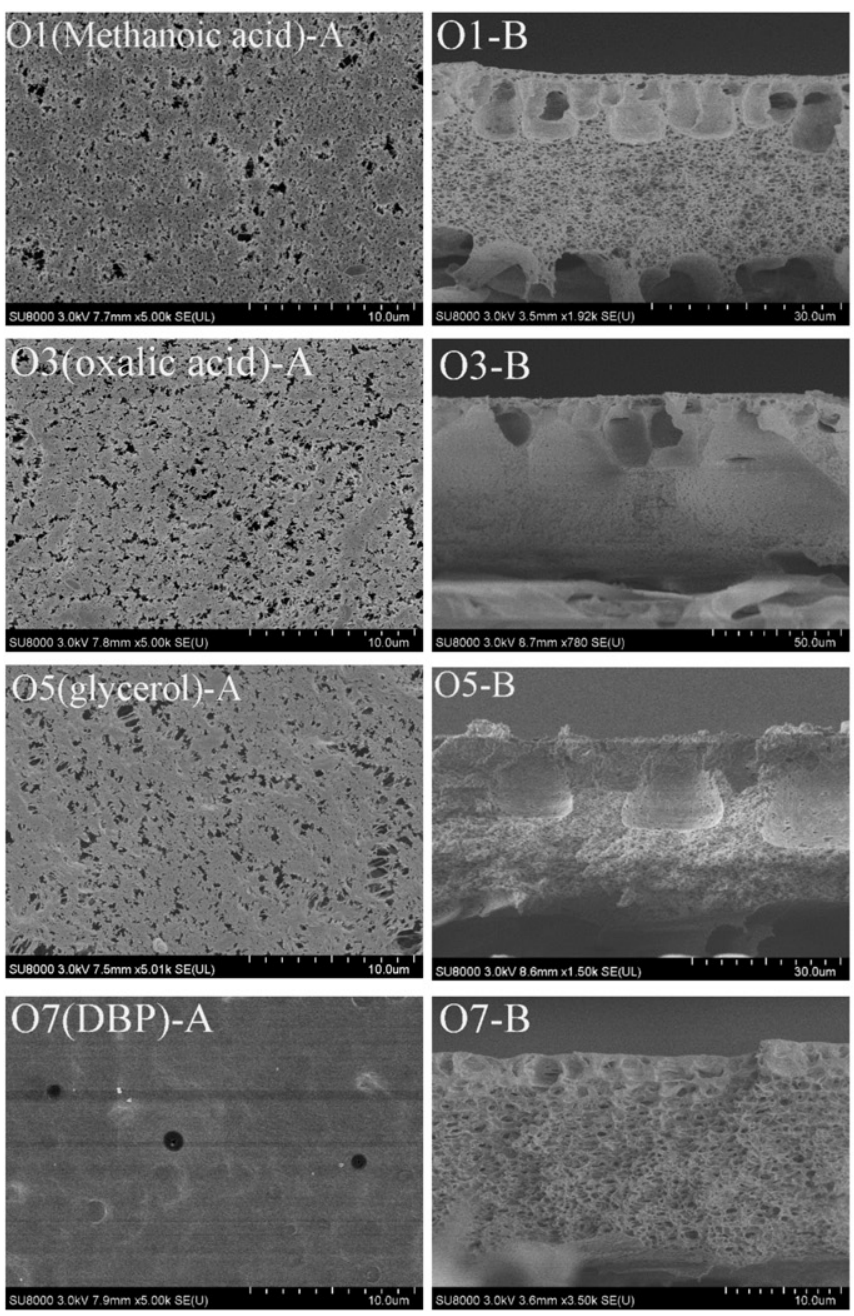
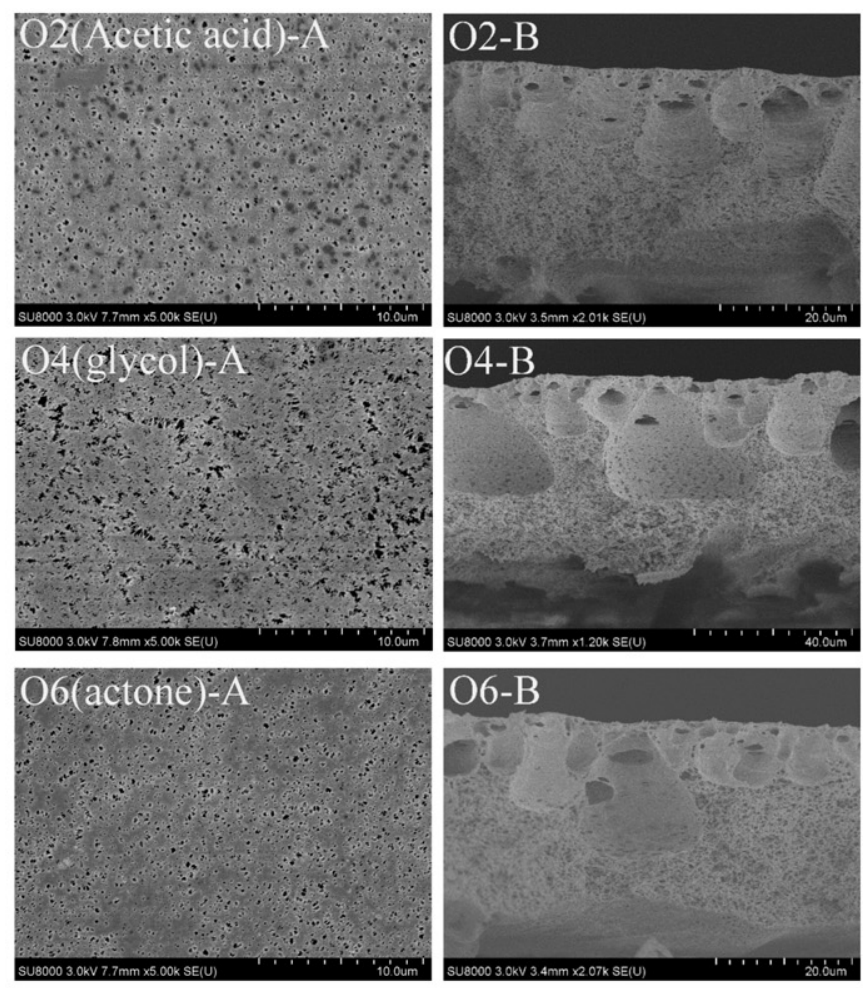

Fig. 4 - Morphology flat-sheet membranes cast from different organic micromolecule additives. (A) membrane surface, (B) cross-section. 
Table 3 - Essential properties of membranes by organic micromolecule additives.

\begin{tabular}{ccccc}
$\begin{array}{c}\text { Membrane } \\
\text { code }\end{array}$ & $\begin{array}{c}\text { Bubble point } \\
\text { size }(\mu \mathrm{m})\end{array}$ & $\begin{array}{c}\text { Mean pore } \\
\text { size }(\mu \mathrm{m})\end{array}$ & $\begin{array}{c}\text { Porosity } \\
(\%)\end{array}$ & $\begin{array}{c}\mathrm{CA}_{\text {water }} \\
\left({ }^{\circ}\right)\end{array}$ \\
\hline O1 & 0.5148 & 0.1104 & 58.38 & 92.1 \\
O2 & 0.2831 & 0.1346 & 56.03 & 93.2 \\
O3 & 3.371 & 0.1686 & 66.38 & 94.1 \\
O4 & 0.3533 & 0.1367 & 63.31 & 95.2 \\
O5 & 0.6374 & 0.2281 & 64.32 & 81.9 \\
O6 & 0.2297 & 0.1344 & 53.51 & 92.6 \\
O7 & 0.0995 & 0.0836 & 42.31 & 94.5 \\
\hline
\end{tabular}

ethanol solution (a low surface energy liquid) and distilled water sequentially for $24 \mathrm{hr}$ each, and it was assumed that all the pores in the membrane were completely filled with water. Then the weight of the wet membrane and dry membrane (which was dried in an oven at $60^{\circ} \mathrm{C}$ ) was measured. The membrane porosity $(\varepsilon)$ was calculated by the following equation:

$\varepsilon=\frac{\left(M_{\mathrm{w}}-\mathrm{M}_{\mathrm{d}}\right) / \rho_{\mathrm{w}}}{\left(\mathrm{M}_{\mathrm{w}}-\mathrm{M}_{\mathrm{d}}\right) / \rho_{\mathrm{w}}+\mathrm{M}_{\mathrm{d}} / \rho_{\mathrm{p}}}$

where $M_{w}$ is the weight of the wet membrane, $M_{d}$ is the weight of the dry membrane, $\rho_{\mathrm{w}}$ and $\rho_{\mathrm{p}}$ are the density of water and polymer, respectively.
The bubble point size, pore size and pore size distribution of the flat sheet membrane were investigated by the gas permeation method using a Capillary Flow Porometer (Porolux 1000, Porolux, Belgium). The membrane samples were completely wetted with Porefil@ (Porolux, Belgium), and tightly fixed on the testing apparatus. Pure nitrogen was then allowed to flow into the sample chamber and the pressure increased gradually as the pressure and permeation flow rates were recorded. Finally, the bubble point size, pore size and pore size distribution were calculated by the measurement system.

\subsection{Desalination experiment by DCMD}

The desalination performance of the PVDF-CTFE membranes was evaluated using a lab-scale DCMD set-up as shown in Fig. 1a, which has been reported in other work (Hou et al., 2012a). The hot feed was a $35 \mathrm{~g} / \mathrm{L}$ sodium chloride solution, the temperature and flow rate of which were kept constantly at $55^{\circ} \mathrm{C}$ and $65 \mathrm{~L} / \mathrm{hr}$, respectively. The cold permeate was a mixture of distilled water and permeate water, whilst the operation temperature and flow rates were $25^{\circ} \mathrm{C}$ and $50 \mathrm{~L} / \mathrm{hr}$. The flat-sheet membrane module consisted of two self-designed polymethyl methacrylate (PMMA) plates as shown in Fig. 1b. The flat-sheet membrane, with an effective area of $5.218 \times 10^{-3} \mathrm{~m}^{2}$, was tightly clamped between
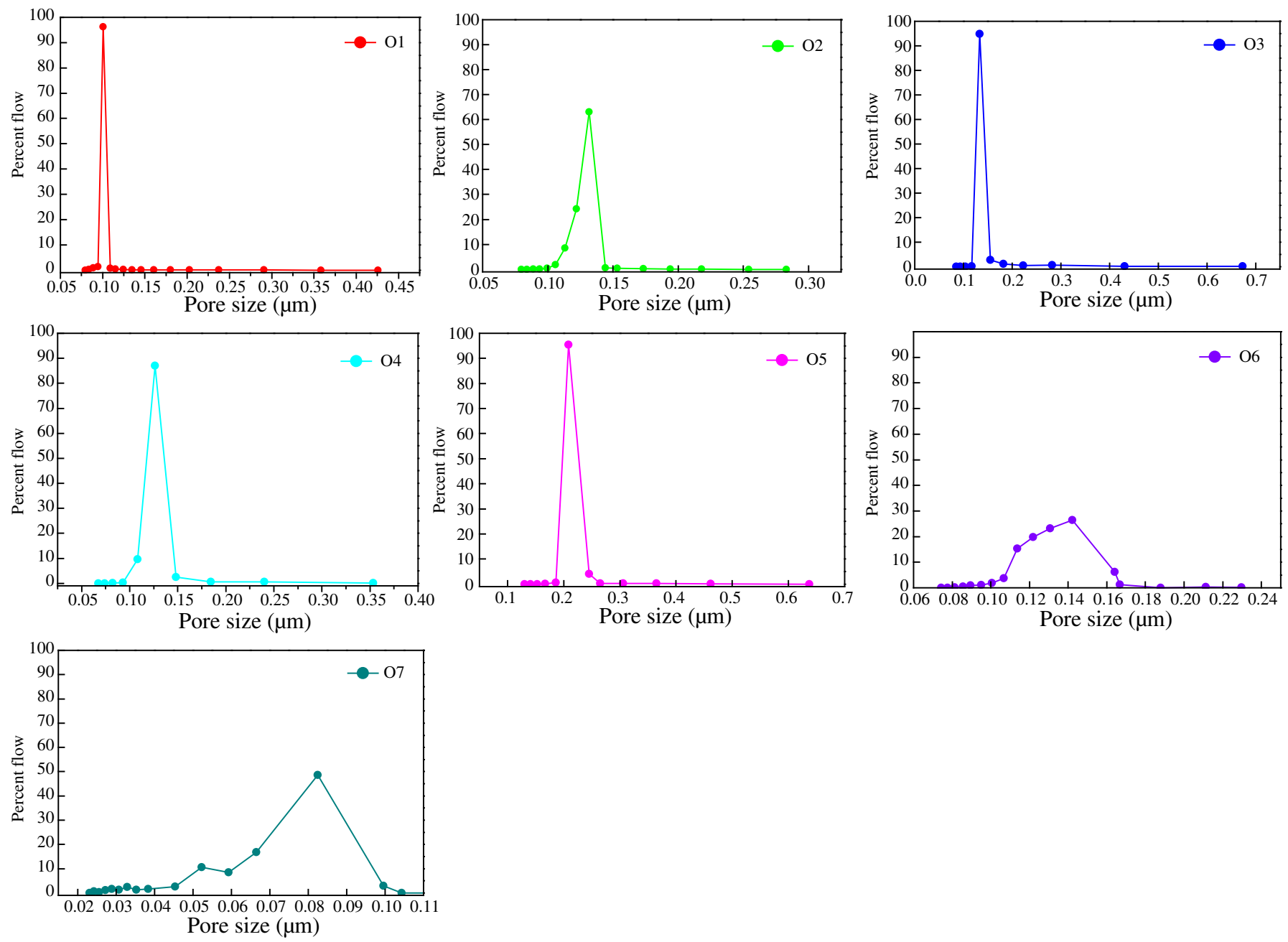

Fig. 5 - Pore distribution of flat-sheet membranes cast from different organic micromolecule additives. 


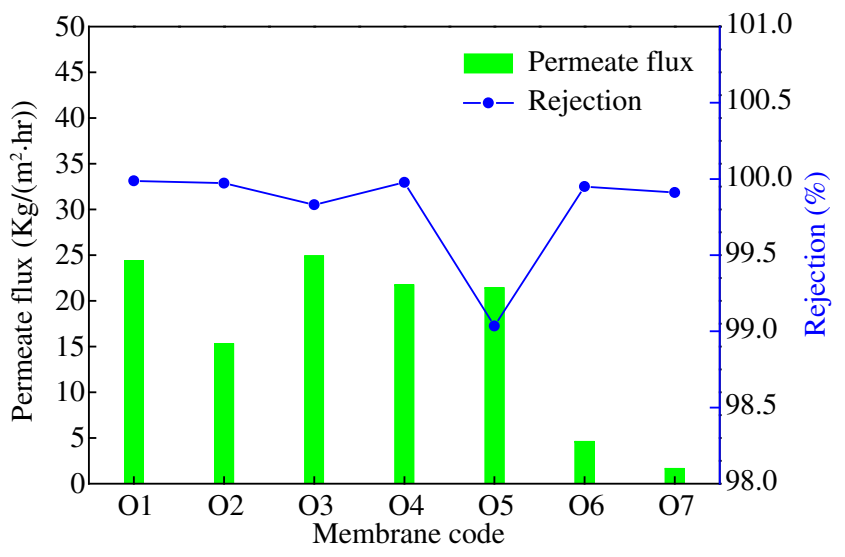

Fig. 6 - DCMD performance of flat-sheet membranes cast from different organic micromolecule additives.

the plates. The co-current configuration was used and the module was placed vertically to avoid the accumulation of gas bubbles.

The concentration of $\mathrm{NaCl}$ in the distillate was monitored with a conductivity meter (CM-230A, Shijiazhuang Create Instrumentation Technologies, China). The permeate flux (J) was calculated using the following equation:

$J=\frac{M}{A \times T}$

where $J\left(\mathrm{~kg} /\left(\mathrm{m}^{2} \cdot \mathrm{hr}\right)\right)$ is the permeate flux, $M(\mathrm{~kg})$ is the weight of distillate, $A\left(\mathrm{~m}^{2}\right)$ is the membrane effective area and $\mathrm{T}(\mathrm{hr})$ represents the sampling time. The rejection coefficient $R$ was calculated according to the following equation:

$R=\frac{C_{f}-C_{p}}{C_{f}}$

where $C_{f}$ and $C_{p}$ are the salt concentrations of the feed and permeate, respectively.

\section{Results and discussion}

\subsection{Effect of polymer additives}

PVP and PEG, which are commonly used polymer membrane additives and have shown favorable structure-controlling capability to enhance membrane performance, were applied to prepare PVDF-CTFE hydrophobic membranes.

Fig. 2 shows the variation of membrane morphology when PVP and PEG were added into the membrane solution. The pores in the surface of membrane P1 were circular with the lowest porosity, and the walls of pores were impervious over the whole cross-section. When PEG or PVP was added, the pore interconnectivity and porosity were significantly increased, both in membrane surface and cross-section. The macrovoids increased significantly with the addition of the additives, especially for P3, where the macrovoids span the entire cross-section and tend to merge to form bigger pores. This can be attributed to the pore-forming effect of PVP and PEG, which derives from the effect of PVP or PEG on the thermodynamic and kinetic properties of the casting solution and the resulting variation of phase inversion
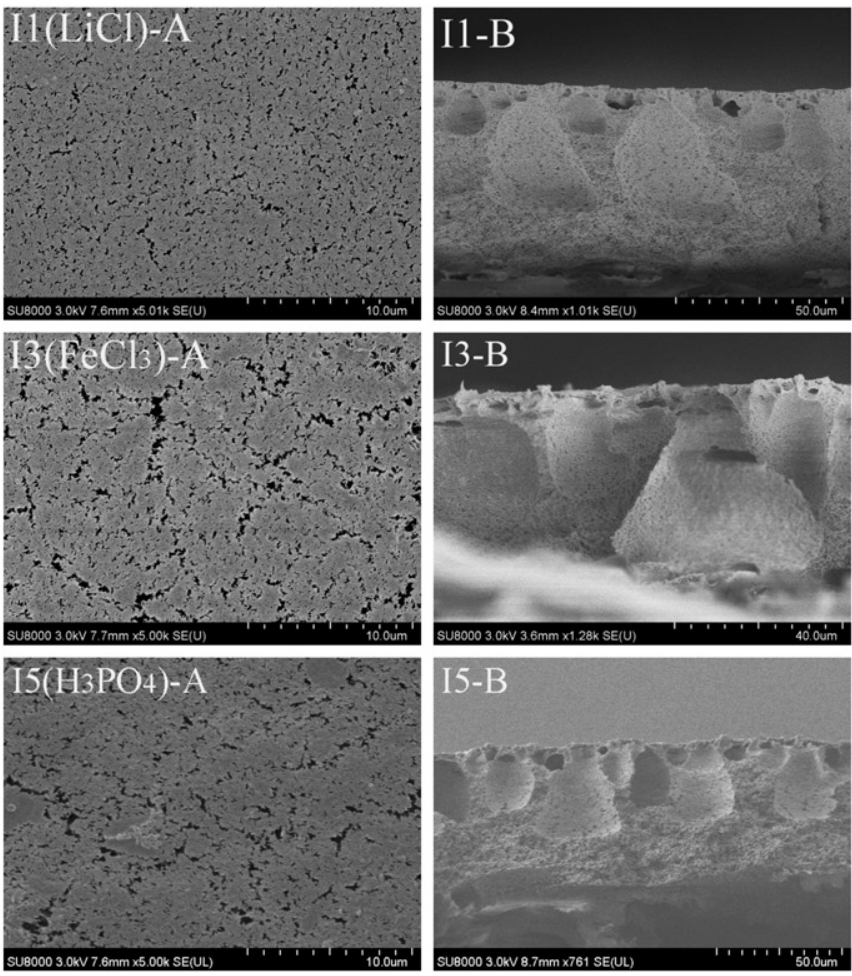
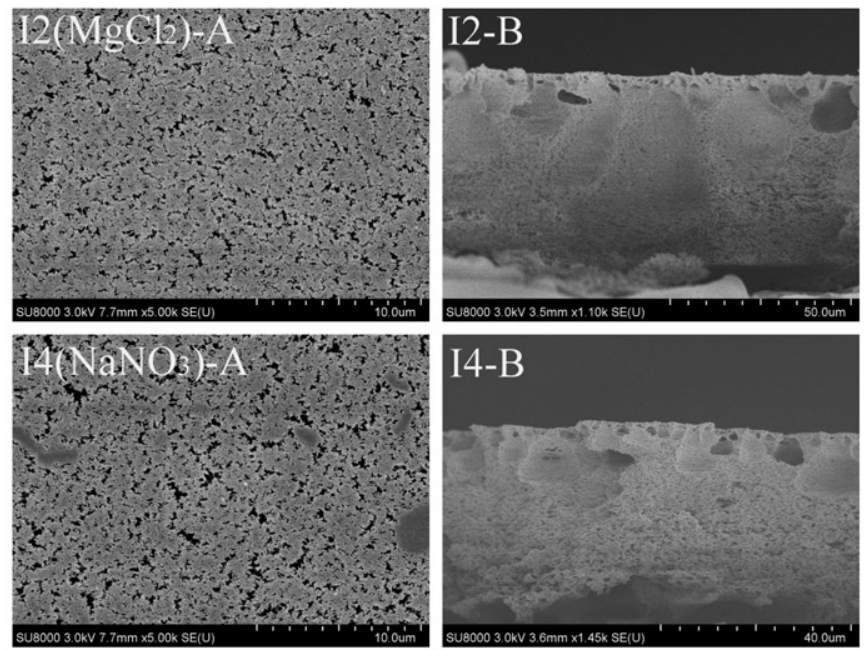

Fig. 7 - Morphology flat-sheet membranes cast from different inorganic additives. (A) Membrane surface, (B) cross-section. 
Table 4 - Essential properties of membranes by inorganic salts and acids additives.

\begin{tabular}{ccccc}
$\begin{array}{c}\text { Membrane } \\
\text { code }\end{array}$ & $\begin{array}{c}\text { Bubble point } \\
\text { size }(\mu \mathrm{m})\end{array}$ & $\begin{array}{c}\text { Mean pore } \\
\text { size }(\mu \mathrm{m})\end{array}$ & $\begin{array}{c}\text { Porosity } \\
(\%)\end{array}$ & $\begin{array}{c}\mathrm{CA}_{\text {water }} \\
\left({ }^{\circ}\right)\end{array}$ \\
\hline I1 & 0.3306 & 0.1133 & 70.88 & 97.5 \\
I2 & 0.3765 & 0.1117 & 72.27 & 93.2 \\
I3 & 0.7336 & 0.1383 & 74.39 & 82.7 \\
I4 & 0.1779 & 0.0881 & 64.24 & 94.6 \\
I5 & 0.3632 & 0.1745 & 66.71 & 99.2 \\
\hline
\end{tabular}

route and rate (Arthanareeswaran et al., 2010; Chakrabarty et al., 2008).

Table 2 presents essential properties and MD performance of the resultant membranes. The pore size and porosity were consistent with membrane thickness, as clearly shown in Fig. 2. The pore size distributions of these 3 membranes are shown in Fig. 3. The bubble point size, mean pore size, and distribution scope were increased with addition of the additives, especially for PVP.

The additives also had an effect on membrane hydrophobicity, with the contact angle with water decreasing from $97.3^{\circ}$ to $88^{\circ}$ and $82.2^{\circ}$ for membranes prepared from PEG and PVP, respectively. Two reasons were responsible for this decrease: one is the residual of additives in membrane matrix (Feng et al., 2006); the other one is the effect on membrane morphology by the additives, especially on the surface due to the thermodynamic and kinetic effects during phase inversion, as the surface roughness has a huge influence on membrane hydrophobicity (Rafat et al., 2006).

As a consequence of the effect on membrane morphology and properties, especially membrane pore size, the membrane performance in MD was significantly influenced. For P3, the membrane was not suitable for MD application due to its oversized pores; while P2 achieved a flux at $17.98 \mathrm{~kg} /\left(\mathrm{m}^{2} \cdot \mathrm{hr}\right)$, increased by $37.67 \%$ compared to the membrane prepared without additive (P1), with salt rejection higher than $99.99 \%$. The promotion in flux was believed to be related to the increase in pore size and pore interconnectivity. So, PEG was considered to be an effective additive for PVDF-CTFE membrane preparation

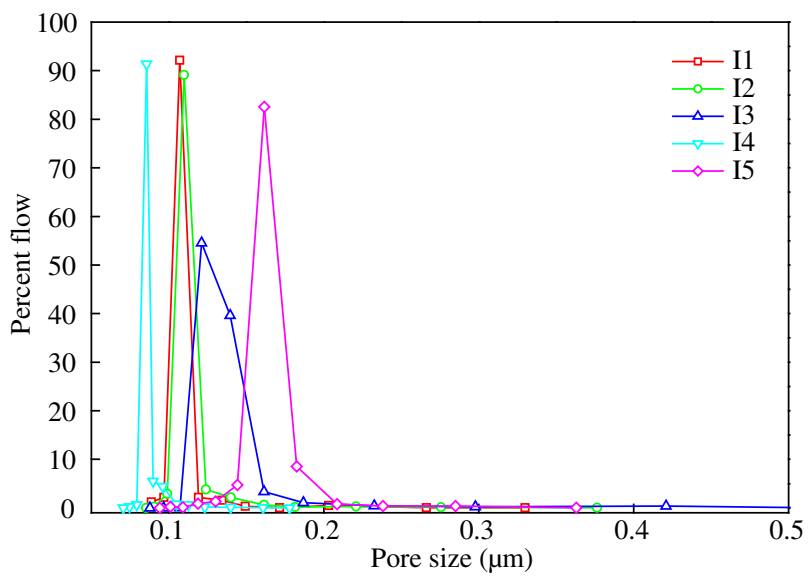

Fig. 8 - Pore distribution of flat-sheet membranes cast from different inorganic additives. For I1-I5 refer to Table 1. and PVP was excluded due to its strong pore-forming effect during our experiment.

\subsection{Effect of organic micromolecule additives}

Organic micromolecules are another type of additive, which are believed to be able to be easily removed from the membrane main structure. This work also focused on the effect of this type of additive on PVDF-CTFE membranes. Methanoic acid, acetic acid, oxalic acid, glycol, glycerol, and DBP were used as additives and their influence on membrane properties and performance were investigated.

The surface and cross-section morphology and pore structure of membranes can be seen in Fig. 4. Membranes 01 to 05 showed an interconnected pore structure and crystals appeared in the membrane cross-section, which may have been induced by the interaction among additives, polymer, and solvent. As organic acids and alcohols had strong interactions with the solvent and polymer and could be leached out quickly, the phase inversion took place quickly, which favors the liquid-liquid demixing process. Therefore, a typical asymmetric cross-section was formed with a top layer, macrovoids, and sponge-like sub-layer. It is also believed that $-\mathrm{OH}$ containing additives tend to form hydrogen bonds with $-\mathrm{OH}$ and $-\mathrm{COOH}$ in the polymer chains. A pre-gelation process may take place before coagulation, and these additives may act as a physical inter-connector between polymer-rich phases in the gelled system (Feng et al., 2006; Sukitpaneenit and Chung, 2009; Wang et al., 2006).

For organic acids, the pore-forming effect increased along with the molecular weight, as shown in Fig. 4 for membranes $\mathrm{O} 1$ to 03. It also can be observed that their effects on membrane surface were different. $\mathrm{O} 1 \mathrm{had}$ an uneven pore distribution, with the appearance of macrovoids with a size greater than $1 \mu \mathrm{m}$, while the pores in $\mathrm{O} 2$ were relatively uniform. Oxalic acid was a strong pore-former, with a larger pore size and higher pore interconnectivity in both surface and cross-section. Glycol and glycerol had the same pore-forming effect on membranes, while uneven big pore defects were observed in membrane $\mathrm{O5}$, and the pore interconnectivity was lower compared to O4. Acetone was not an effective pore-former compared to the membrane without additives. Because acetone evaporated quickly during exposure in air, the swelling action will result in a non-uniform structure

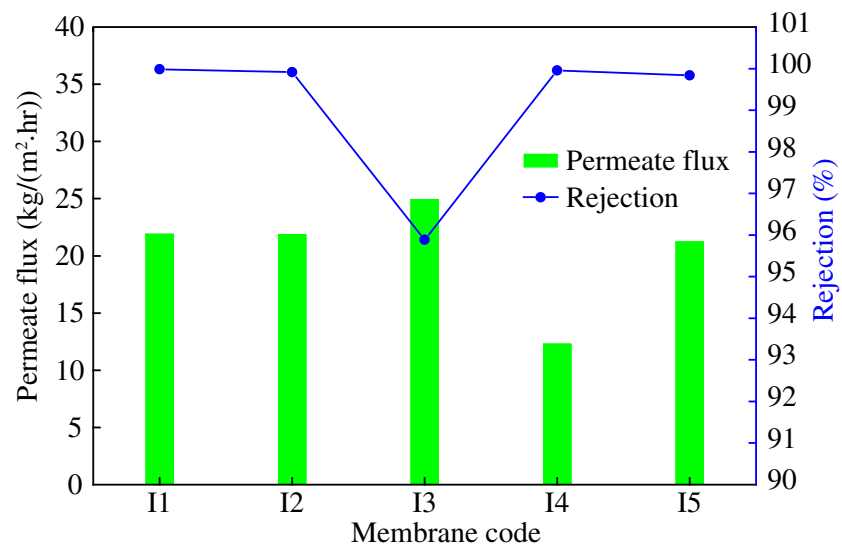

Fig. 9 - DCMD performance of flat-sheet membranes cast from different inorganic additives. 

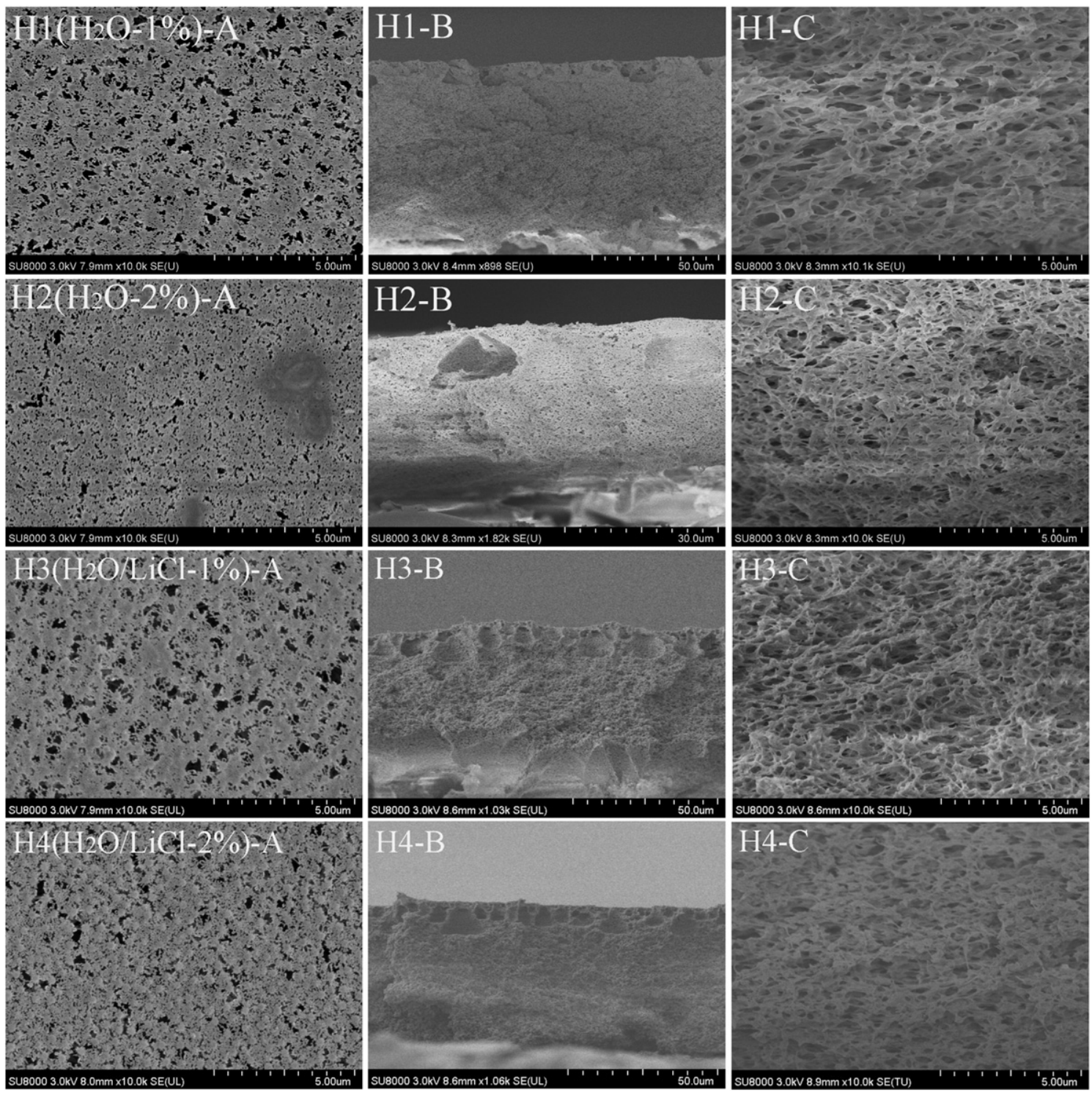

Fig. 10 - Morphology flat-sheet membranes cast from $\mathrm{H}_{2} \mathrm{O}$ and $\mathrm{LiCl} / \mathrm{H}_{2} \mathrm{O}$ mixture. (A) Membrane surface, (B) cross-section, (C) magnified structure of sponge-like layer.

(Hou et al., 2012a). Furthermore, DBP appears not to be a suitable additive in membranes for MD, because it has a symmetric membrane cross-section structure with a nonporous surface. As DBP is hydrophobic, its affinity to water is low. Thus the phase inversion process was seriously delayed, and a symmetric and nonporous structure formed resulting from the solidification of the polymer-rich phase. However, this was an interesting finding, and this effect by DBP may enable some flexibility in other membrane process.

The pore structure and hydrophobicity of membranes are presented in Table 3. It was clear that all these additives have only a slight influence on membrane hydrophobicity except for glycerol, as compared to membranes prepared without additive $\left(97.3^{\circ}\right)$. The influence on membrane surface roughness is one reason, and the ease of the additives' removal from the membrane matrix was another important reason, as compared to the polymer additives PVP and PEG. And as found by SEM in Fig. 4, membrane $\mathrm{O} 3$ had the highest porosity, while
O7 had the smallest pore size and porosity because of the pore-suppressing effect of DBP. Because membrane 07 had an uneven pore distribution (Fig. 5), in consideration of the small pore size and porosity, the measurement method used in this work may not suitable for this membrane. However, PVDF-CTFE membranes from other additives presented a concentrated distribution as shown in Fig. 5.

The resultant membranes prepared by these micromolecule additives were also tested by DCMD, and the permeate flux and salt rejection are presented in Fig. 6. Membrane 07 had the smallest flux due to the nonporous structure, which was consistent with it having the lowest pore size and porosity. Membrane 05 had the lowest salt rejection and the conductivity increased quickly during MD operation, while other membranes presented a rejection higher than $99.9 \%$. The membrane 03 had the highest flux of $24.86 \mathrm{~kg} / \mathrm{m}^{2} \cdot \mathrm{hr}$ with a rejection of $99.83 \%$, which was higher than in previous reports (Alkhudhiri et al., 2012; Hou et al., 2014). 


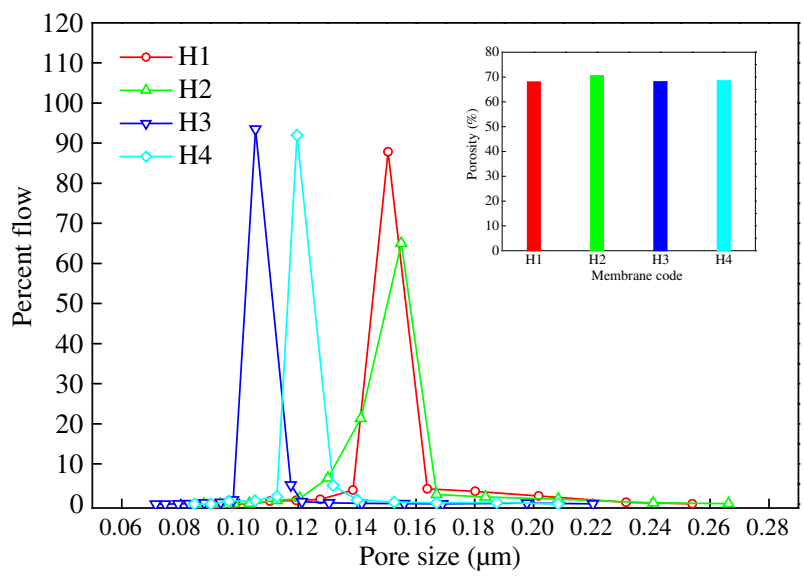

Fig. 11 - Pore distribution and porosity of membranes prepared by $\mathrm{H}_{2} \mathrm{O}$ and $\mathrm{LiCl} / \mathrm{H}_{2} \mathrm{O}$ mixture. For $\mathrm{H} 1-\mathrm{H} 4$ refer to Table 1.

\subsection{Effect of inorganic additives}

Inorganic salts and acids are also widely used additives for polymer membrane preparation, so $\mathrm{LiCl}, \mathrm{MgCl}_{2}, \mathrm{FeCl}_{3}, \mathrm{NaNO}_{3}$, and $\mathrm{H}_{3} \mathrm{PO}_{4}$ were investigated at a concentration of $5 \%$ in PVDF-CTFE membrane solution in this work. Their influence on membrane morphology can be seen in Fig. 7. It can be observed that the pore size increased as the valence of the metal cation increased, both on the surface and in cross-section. The membrane prepared with $\mathrm{H}_{3} \mathrm{PO}_{4}$ showed an uneven pore distribution on the membrane surface. Although some large pores were observed in the membrane surface, the pore interconnectivity of membrane I5 was low, while the pore interconnectivity of I1 to I4 was high. It is believed that the cation in metal salt additives undergoes reaction with the solvent and polymer, which will have an effect on the phase inversion process (Jungbaurer and Curran, 1964; Noor et al., 2013). The viscosity of the membrane will be increased significantly, influencing the phase inversion process. Generally, pre-gelation may take place, as the addition of metal salts and the resultant membrane will show an interconnected pore structure as shown in Fig. 7. In addition, during the coagulation process, the strong interaction with solvent and polymer also benefit the S-L demixing.

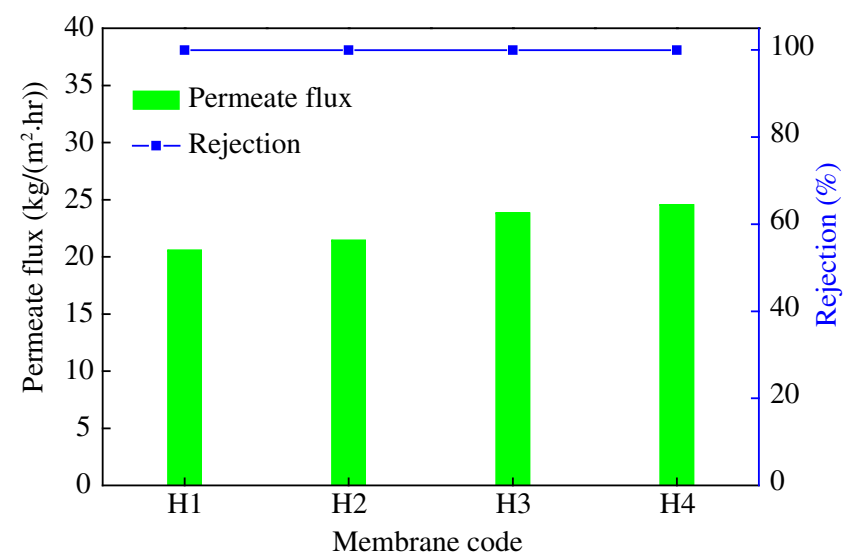

Fig. 12 - DCMD performance of flat-sheet membranes cast from $\mathrm{H}_{2} \mathrm{O}$ and $\mathrm{LiCl} / \mathrm{H}_{2} \mathrm{O}$ mixture.
Consequently, the pore interconnectivity increased due to the appearance of crystals in the membrane.

The pore size and porosity of membranes (shown in Table 4) present the same trends as the morphology, such that the membranes prepared with the trivalent salt $\mathrm{FeCl}_{3}$ and monovalent salt $\mathrm{NaNO}_{3}$ have the biggest and smallest pore size and porosity, respectively. The membrane pore distribution also presented the same trend; as can be seen in Fig. 8, all membranes showed a relatively centralized distribution. The membrane hydrophobicity was only slightly affected by the addition of the inorganic additives with the exception of $\mathrm{FeCl}_{3}$; the $\mathrm{CA}_{\text {water }}$ of each membrane was higher than $93^{\circ}$, which was similar to that of the membrane prepared without additives. As for $\mathrm{FeCl}_{3}$, $\mathrm{FeOOH}$ or $\mathrm{Fe}_{2} \mathrm{O}_{3}$ are formed and remain in the membrane, so the hydrophobicity is significantly decreased (Ma et al., 2009).

Fig. 9 presents the results of membrane flux and rejection as measured by the DCMD test. Membrane I3 has the highest flux because its pore size is the largest, while the rejection was low and the conductivity increased during the MD process, indicating that the saline water crossed the membrane into the permeate. It is safe to say that membrane separation properties were mostly consistent with the pore structures. Thus the membranes prepared by $\mathrm{LiCl}$ and $\mathrm{MgCl}_{2}$ showed the same separation due to their similar pore structures, while the membrane prepared with the $\mathrm{NaNO}_{3}$ additive had the lowest flux.

\subsection{Effect of non-solvent additive $\mathrm{H}_{2} \mathrm{O}$}

The effect of the non-solvent $\mathrm{H}_{2} \mathrm{O}$ on PVDF-CTFE/DMAc and PVDF-CTFE/DMAc/LiCl was investigated, and the membrane morphologies are presented in Fig. 10. Two conspicuous changes appeared when $\mathrm{H}_{2} \mathrm{O}$ was added to the casting solution as seen by comparing membranes $\mathrm{H} 1$ and $\mathrm{H} 2$ with membrane P1. One was the significant increase in pore interconnectivity and porosity in both the membrane surface and cross-section; the other one was the appearance of crystals. As $\mathrm{H}_{2} \mathrm{O}$ was added, partial phase inversion may take place before the coagulation process, which has been described as pre-gelation (Lin et al., 2002). Because this offers enough time for S-L demixing (crystallization), this process was beneficial for high porosity and pore interconnectivity. This also explains the increase in pore interconnectivity and the number of crystals when the addition of $\mathrm{H}_{2} \mathrm{O}$ was increased, as shown with H2. Furthermore, the solid-liquid demixing exerted more influence over liquid-liquid demixing when $\mathrm{LiCl} / \mathrm{H}_{2} \mathrm{O}$ mixed additives were applied because of the interaction between $\mathrm{LiCl}$ and other components. As a consequence, the pore interconnectivity was further increased and significantly more crystals can be found in both the membrane surface and cross-section, especially when more $\mathrm{H}_{2} \mathrm{O}$ was added as shown for membrane $\mathrm{H} 4$. The synergetic effect of $\mathrm{LiCl}$ and $\mathrm{H}_{2} \mathrm{O}$ may further increase the viscosity of the membrane solution and benefit the crystallization process.

The pore structure of the membranes is shown in Fig. 11, which shows the bubble point size, mean pore size, pore distribution, and porosity. Membrane H2 had the highest porosity, with a relatively broad distribution. That may be explained by the defects present in the membrane cross-section, as shown in Fig. 10, which may be induced by the prior partial phase inversion process, as the addition of 
$\mathrm{H}_{2} \mathrm{O}$ was high. The membranes with higher $\mathrm{H}_{2} \mathrm{O}$ addition had higher pore size, and the addition of LiCl slightly decreased the pore size. However, the membrane porosity was not clearly influenced during this preparation condition.

The MD flux and salt rejection of the resultant membranes are shown in Fig. 12, as well as the $\mathrm{CA}_{\text {water }}$ of the membranes. The flux increased as the content of $\mathrm{H}_{2} \mathrm{O}$ increased and with the addition of the second additive $\mathrm{LiCl}$, while the salt rejection of each membrane was higher than $99.96 \%$. It can also be observed that the application of mixed additives significantly improved the membrane permeability as compared to the membrane prepared with a single $\mathrm{LiCl}$ additive. The flux and rejection of membrane H4 were $24.53 \mathrm{~kg} / \mathrm{m}^{2} \cdot \mathrm{hr}$ and $99.98 \%$ during DCMD operation, which is relatively high compared to other work as far as we know.

\section{Conclusions}

In this paper, PVDF-CTFE copolymer was used to prepare hydrophobic membranes for MD applications. The effect of four common types of additives, i.e., polymer additives, organic micromolecule additives, inorganic salts and acids, and the strong non-solvent $\mathrm{H}_{2} \mathrm{O}$, was investigated in terms of membrane morphology, properties, and DCMD testing. The following conclusions were reached during this work.

1. PEG was found to be an effect additive for PVDF-CTFE membrane preparation, as the resultant membrane showed good performance in MD. However, PVP was not suitable for hydrophobic membrane preparation due to its strong pore-forming effect.

2. Inorganic and organic micromolecule additives can diffuse out easily, so they have only slight influence on membrane hydrophobicity, except for glycerol and $\mathrm{FeCl}_{3}$.

3. Organic acids and alcohols may react with polymer and solvent due to the presence of hydroxyl groups, while metal salts will form complexes between the anion and the polymer. This induces the pre-gelation process, and the resultant membrane has high interconnectivity with crystals observed in the membrane.

4. Acetone was not an effective additive due to its swelling action in the casting solution, while DBP presents a pore-suppressing effect because of its hydrophobic nature. $\mathrm{FeCl}_{3}$ has a strong pore-forming effect but significantly decreases the membrane hydrophobicity due to residues of $\mathrm{FeOOH}$ or $\mathrm{Fe}_{2} \mathrm{O}_{3}$.

5. Pre-gelation had more significant impact when $\mathrm{H}_{2} \mathrm{O}$ was used as additive, especially when $\mathrm{LiCl}$ was added as the second additive. Conspicuous crystals appeared due to the crystallization process, and the interconnectivity and porosity of the resultant membranes were high.

6. Membranes prepared with glycerol and $\mathrm{LiCl} / \mathrm{H}_{2} \mathrm{O}$ mixture additives achieved a permeate flux of $24.86 \mathrm{~kg} / \mathrm{m}^{2} \cdot \mathrm{hr}$ and $24.53 \mathrm{~kg} / \mathrm{m}^{2} \cdot \mathrm{hr}$, respectively. In addition, the salt rejection was higher than $99.95 \%$ due to the high hydrophobicity and fine pore structure.

7. PVDF-CTFE copolymer has potential in hydrophobic membrane preparation and application, and mixed additive selection and membrane modification should be two directions for future research.

\section{Acknowledgments}

The authors would like to thank Professor Wang Fei of Tsinghua University for the AFM test and her valuable discussion and suggestions. Financial support by the National Natural Science Foundation of China (Nos. 51378491, 51578533, 21307149) is also gratefully acknowledged.

\section{R E F E R E N C E S}

Alkhudhiri, A., Darwish, N., Hilal, N., 2012. Membrane distillation: A comprehensive review. Desalination 287, 2-18.

Ameduri, B., 2009. From vinylidene fluoride (VDF) to the applications of VDF-containing polymers and copolymers: Recent developments and future trends. Chem. Rev. 109, 6632-6686.

Arthanareeswaran, G., Mohan, D., Raajenthiren, M., 2010. Preparation, characterization and performance studies of ultrafiltration membranes with polymeric additive. J. Membr. Sci. 350, 130-138.

Chakrabarty, B., Ghoshal, A., Purkait, M., 2008. Preparation, characterization and performance studies of polysulfone membranes using PVP as an additive. J. Membr. Sci. 315, 36-47.

Cheng, L.P., 1999. Effect of temperature on the formation of microporous PVDF membranes by precipitation from 1octanol/DMF/PVDF and water/DMF/PVDF systems. Macromolecules 32, 6668-6674.

Cheng, L.P., Lin, D.J., Shih, C.H., Dwan, A.H., Gryte, C.C., 1999. PVDF membrane formation by diffusion-induced phase separationmorphology prediction based on phase behavior and mass transfer modeling. J. Polym. Sci. Polym. Phys. 37, 2079-2092.

Cheng, L.P., Young, T.H., Chuang, W.-Y., Chen, L.Y., Chen, L.W., 2001. The formation mechanism of membranes prepared from the nonsolvent-solvent-crystalline polymer systems. Polymer 42, 443-451.

Cui, Z., Drioli, E., Lee, Y.M., 2014. Recent progress in fluoropolymers for membranes. Prog. Polym. Sci. 39, 164-198.

Dang, H.T., Amelot, C., Rana, D., Narbaitz, R.M., Matsuura, T., 2010. Performance of a newly developed hydrophilic additive blended with different ultrafiltration base polymers. J. Appl. Polym. Sci. 116, 2205-2215.

Feng, C., Shi, B., Li, G., Wu, Y., 2004. Preparation and properties of microporous membrane from poly (vinylidene fluoride-cotetrafluoroethylene)(F2. 4) for membrane distillation. J. Membr. Sci. 237, 15-24.

Feng, C., Wang, R., Shi, B., Li, G., Wu, Y., 2006. Factors affecting pore structure and performance of poly (vinylidene fluorideco-hexafluoro propylene) asymmetric porous membrane. J. Membr. Sci. 277, 55-64.

Hou, D., Dai, G., Wang, J., Fan, H., Zhang, L., Luan, Z., 2012 a. Preparation and characterization of PVDF/nonwoven fabric flat-sheet composite membranes for desalination through direct contact membrane distillation. Sep. Purif. Technol. 101, $1-10$.

Hou, D., Fan, H., Jiang, Q., Wang, J., Zhang, X., 2014. Preparation and characterization of PVDF flat-sheet membranes for direct contact membrane distillation. Sep. Purif. Technol. 135, 211-222.

Hou, D., Wang, J., Sun, X., Ji, Z., Luan, Z., 2012b. Preparation and properties of PVDF composite hollow fiber membranes for 
desalination through direct contact membrane distillation. J. Membr. Sci. 405, 185-200.

Idris, A., Ahmed, I., Limin, M.A., 2010. Influence of lithium chloride, lithium bromide and lithium fluoride additives on performance of polyethersulfone membranes and its application in the treatment of palm oil mill effluent. Desalination 250, 805-809.

Jungbaurer, M., Curran, C., 1964. $\mathrm{NC}=\mathrm{O}$ bending vibration in complexes of dimethylformamide with metal halides. Nature 202, 290.

Kang, G.D., Cao, Y.M., 2014. Application and modification of poly (vinylidene fluoride)(PVDF) membranes-A review. J. Membr. Sci. 463, 145-165.

Khayet, M., Feng, C., Khulbe, K., Matsuura, T., 2002. Study on the effect of a non-solvent additive on the morphology and performance of ultrafiltration hollow-fiber membranes. Desalination 148, 321-327.

Koh, J.H., Kim, Y.W., Park, J.T., Min, B.R., Kim, J.H., 2008. Nanofiltration membranes based on poly (vinylidene fluorideco-chlorotrifluoroethylene)-graft-poly (styrene sulfonic acid). Polym. Adv. Technol. 19, 1643-1648.

Kraus, M., Nemas, M., Frommer, M., 1979. The effect of low molecular weight additives on the properties of aromatic polyamide membranes. J. Appl. Polym. Sci. 23, 445-452.

Kurdi, J., Tremblay, A., 2001. The influence of casting solution structure on the microporosity of polyetherimide gas separation membranes prepared by the coagulation postleaching method. J. Membr. Sci. 184, 175-186.

Lin, K.Y., Wang, D.M., Lai, J.Y., 2002. Nonsolvent-induced gelation and its effect on membrane morphology. Macromolecules 35, 6697-6706.

Liu, F., Abed, M.R.M., Li, K., 2011a. Hydrophilic modification of $\mathrm{P}$ (VDF-CO-CTFE) porous membranes. Chem. Eng. Sci. 66, 27-35.

Liu, F., Hashim, N.A., Liu, Y., Abed, M.M., Li, K., 2011b. Progress in the production and modification of PVDF membranes. J. Membr. Sci. 375, 1-27.

Ma, J., Wang, Z., Pan, M., Guo, Y., 2009. A study on the multifunction of ferrous chloride in the formation of poly (vinylidene fluoride) ultrafiltration membranes. J. Membr. Sci. 341, 214-224.

Mansourizadeh, A., Ismail, A.F., 2011. Preparation and characterization of porous PVDF hollow fiber membranes for CO 2 absorption: Effect of different non-solvent additives in the polymer dope. Int. J. Greenhouse Gas Control 5, 640-648.
Noor, N.D.M., Yusof, N.M., Ahmed, I., Hesampour, M., Idris, A., 2013. Influence of sodium bromide additive on polyethersulfone ultrafiltration membranes. J. Appl. Polym. Sci. 128, 1746-1755.

Pezeshk, N., Rana, D., Narbaitz, R., Matsuura, T., 2012. Novel modified PVDF ultrafiltration flat-sheet membranes. J. Membr. Sci. 389, 280-286.

Rafat, M., De, D., Khulbe, K., Nguyen, T., Matsuura, T., 2006. Surface characterization of hollow fiber membranes used in artificial kidney. J. Appl. Polym. Sci. 101, 4386-4400.

Shih, H., Yeh, Y., Yasuda, H., 1990. Morphology of microporous poly (vinylidene fluoride) membranes studied by gas permeation and scanning electron microscopy. J. Membr. Sci. 50, 299-317.

Shinde, M., Kulkarni, S., Musale, D., Joshi, S., 1999. Improvement of the water purification capability of poly (acrylonitrile) ultrafiltration membranes. J. Membr. Sci. 162, 9-22.

Sukitpaneenit, P., Chung, T.S., 2009. Molecular elucidation of morphology and mechanical properties of PVDF hollow fiber membranes from aspects of phase inversion, crystallization and rheology. J. Membr. Sci. 340, 192-205.

Wang, D., Li, K., Teo, W., 2000. Porous PVDF asymmetric hollow fiber membranes prepared with the use of small molecular additives. J. Membr. Sci. 178, 13-23.

Wang, Z.G., Xu, Z.K., Wan, L.S., 2006. Modulation the morphologies and performance of polyacrylonitrile-based asymmetric membranes containing reactive groups: Effect of non-solvents in the dope solution. J. Membr. Sci. 278, 447-456.

Wongchitphimon, S., Wang, R., Jiraratananon, R., Shi, L., Loh, C.H., 2011. Effect of polyethylene glycol (PEG) as an additive on the fabrication of polyvinylidene fluoride-co-hexafluropropylene (PVDF-HFP) asymmetric microporous hollow fiber membranes. J. Membr. Sci. 369, 329-338.

Yang, S., Liu, Z., 2003. Preparation and characterization of polyacrylonitrile ultrafiltration membranes. J. Membr. Sci. 222 87-98.

Yeow, M., Liu, Y., Li, K., 2005. Preparation of porous PVDF hollow fibre membrane via a phase inversion method using lithium perchlorate $\left(\mathrm{LiClO}_{4}\right)$ as an additive. J. Membr. Sci. 258, 16-22.

Zheng, Q.Z., Wang, P., Yang, Y.N., 2006. Rheological and thermodynamic variation in polysulfone solution by PEG introduction and its effect on kinetics of membrane formation via phase-inversion process. J. Membr. Sci. 279, 230-237. 